\title{
Correction to: A randomized controlled trial of an intervention delivered by mobile phone app instant messaging to increase the acceptability of effective contraception among young people in Tajikistan
}

Ona McCarthy ${ }^{1 *}$, Irrfan Ahamed ${ }^{1}$, Firuza Kulaeva², Ravshan Tokhirov², Salokhiddin Saibov², Marieka Vandewiele ${ }^{3}$, Sarah Standaert ${ }^{3}$, Baptiste Leurent ${ }^{4}$, Phil Edwards ${ }^{1}$, Melissa Palmer ${ }^{1}$ and Caroline Free ${ }^{1}$

\section{Correction}

After publication of the original article [1], it came to the authors' attention that there is a typo in the Results section. The following section should have read as follows:

Participants' report of physical violence during the study.

Overall, $0.85 \%(4 / 470)$ reported that they experienced physical violence since being in the study $(0.41 \%$ in the control and $1.32 \%$ in the intervention, Pearson's chi2 $p=0.28$ ).

\section{Author details \\ 'Department of Population Health, Faculty of Epidemiology and Population Health, London School of Hygiene \& Tropical Medicine, Keppel Street, London WC1E 7HT, UK. ${ }^{2}$ Tajik Family Planning Association, 10 Rudaki Avenue, TC 'Sadbarg', 7th floor, Dushanbe, Tajikistan. 'International Planned Parenthood Federation European Network, Rue Royale 146, 1000 Brussels, Belgium. ${ }^{4}$ Department of Medical Statistics, Faculty of Epidemiology and Population Health, London School of Hygiene \& Tropical Medicine, Keppel Street, London WC1E 7HT, UK.}

Published online: 26 March 2018

\section{Reference}

1. McCarthy O, et al. A randomized controlled trial of an intervention delivered by mobile phone app instant messaging to increase the acceptability of effective contraception among young people in Tajikistan. Reprod Health. 2018;15:28. https://doi.org/10.1186/s12978-018-0473-z.

\footnotetext{
* Correspondence: ona.mccarthy@lshtm.ac.uk

${ }^{1}$ Department of Population Health, Faculty of Epidemiology and Population Health, London School of Hygiene \& Tropical Medicine, Keppel Street,
}

London WC1E 7HT, UK 